\title{
Outcomes of AIDS-associated Kaposi sarcoma in Mozambique after treatment with pegylated liposomal doxorubicin
}

Matthew E. Coldiron ${ }^{*}$ (D), Ana Gabriela Gutierrez Zamudio ${ }^{2}$, Rolanda Manuel ${ }^{3}$, Gilda Luciano ${ }^{3}$, Barbara Rusch ${ }^{4}$, Iza Ciglenecki ${ }^{4}$, Alex Telnov ${ }^{4}$, Rebecca F. Grais ${ }^{1}$, Laurence Toutous Trellu ${ }^{5}$ and Lucas Molfino ${ }^{2}$

\begin{abstract}
Background: Kaposi's sarcoma (KS) is a common HIV-associated malignancy frequently associated with poor outcomes. It is the most frequently diagnosed cancer in major cities of Mozambique. Antiretroviral therapy is the cornerstone of KS treatment, but many patients require cytotoxic chemotherapy. The traditional regimen in Mozambique includes conventional doxorubicin, bleomycin and vincristine, which is poorly tolerated. In 2016, pegylated liposomal doxorubicin was introduced at a specialized outpatient center in Maputo, Mozambique.

Methods: We performed a prospective, single-arm, open-label observational study to demonstrate the feasibility, safety, and outcomes of treatment with pegylated liposomal doxorubicin (PLD) in patients with AIDS-associated Kaposi sarcoma (KS) in a low-resource setting. Chemotherapy-naïve adults with AIDS-associated KS (T1 or T0 not responding to 6 months of antiretroviral therapy) were eligible if they were willing to follow up for 2 years. Patients with Karnofsky scores $<50$ or contraindications to PLD were excluded. One hundred eighty-three patients were screened and 116 participants were enrolled. Patients received PLD on three-week cycles until meeting clinical stopping criteria. Follow-up visits monitored HIV status, KS disease, side effects of chemotherapy, mental health (PHQ-9) and quality of life (SF-12). Primary outcome measures included vital status and disease status at 6, 12, and 24 months after enrollment.
\end{abstract}

Results: At 24 months, 23 participants (20\%) had died and 15 (13\%) were lost to follow-up. Baseline CD4< 100 was associated with death (HR 2.7, 95\%Cl [1.2-6.2], $p=0.016$ ), as was T1S1 disease compared to T1S0 disease (HR 2.7, $95 \%$ Cl [1.1-6.4], $p=0.023$ ). Ninety-two participants achieved complete or partial remission at any point (overall response rate $80 \%)$, including 15 (13\%) who achieved complete remission. PLD was well-tolerated, and the most common AEs were neutropenia and anemia. Quality of life improved rapidly after beginning PLD.

Discussion: PLD was safe, well-tolerated and effective as first-line treatment of KS in Mozambique. High mortality was likely due to advanced immunosuppression at presentation, underscoring the importance of earlier screening and referral for KS.

Keywords: Kaposi sarcoma, Acquired immunodeficiency syndrome, Mozambique, AIDS-related opportunistic infections, Doxorubicin

\footnotetext{
* Correspondence: matthew.coldiron@epicentre.msf.org

${ }^{1}$ Epicentre, 14-34 Avenue Jean Jaurès, 75019 Paris, France

Full list of author information is available at the end of the article
}

\section{$\triangle B M C$}

C C The Author(s). 2021 Open Access This article is licensed under a Creative Commons Attribution 4.0 International License, which permits use, sharing, adaptation, distribution and reproduction in any medium or format, as long as you give appropriate credit to the original author(s) and the source, provide a link to the Creative Commons licence, and indicate if changes were made. The images or other third party material in this article are included in the article's Creative Commons licence, unless indicated otherwise in a credit line to the material. If material is not included in the article's Creative Commons licence and your intended use is not permitted by statutory regulation or exceeds the permitted use, you will need to obtain permission directly from the copyright holder. To view a copy of this licence, visit http://creativecommons.org/licenses/by/4.0/ The Creative Commons Public Domain Dedication waiver (http://creativecommons.org/publicdomain/zero/1.0/) applies to the data made available in this article, unless otherwise stated in a credit line to the data. 


\section{Introduction}

Kaposi's sarcoma (KS) is a major cause of mortality in sub-Saharan Africa, where it is generally associated with HIV $[1,2]$. In Mozambique, it is the most frequent cancer documented in cancer registers in the major cities of Maputo and Beira [3], with an estimated age-standardized incidence of 23 cases per 100,000 persons per year and 3215 deaths in 2012 alone [4]. In sub-Saharan Africa, KS can be aggressive and have poor outcomes [5]. KS lesions are often visible and painful, leading to physical and psychological disability, and associated stigma may play a role in delayed presentation [6].

The cornerstone of treatment of HIV-associated KS is antiretroviral therapy (ART), which reduces the burden of $\mathrm{KS}$ disease by itself $[7,8]$. Nonetheless, with advanced $\mathrm{KS}$, chemotherapy is often necessary [9]. In high-income countries, first-line chemotherapy consists of liposomal anthracyclines or taxanes [10, 11]. Pegylated liposomal formulations of doxorubicin (PLD) are associated with more favorable outcomes and safety profiles than conventional forms [12-15], but are expensive. In low- and middle-income countries, a combination of bleomycin and vincristine (BV), with or without conventional doxorubicin $(\mathrm{ABV})$ is often still the standard of care. These combinations can be poorly-tolerated and associated with lower quality of life, so better treatment options are necessary [16].

In March 2016, Médecins Sans Frontières (MSF) began offering PLD as first-line chemotherapy for KS in Maputo, Mozambique. A prospective observational study was implemented to document safety, tolerability and effectiveness, with an overall goal of improving clinical practice in a low-resource setting.

\section{Methods}

\section{Study setting}

The Centro de Referencia de Alto-Maé (CRAM) is a collaboration between MSF and the Mozambican Ministry of Health. This intermediate-level, ambulatory care facility bridges the gap between primary clinics and hospitals by ensuring access to specialized services for HIVinfected patients with complications. Between 2010 and 2015, 1567 HIV-positive patients were treated for KS at CRAM. Most had advanced disease at baseline (62\% with T1S0 and 21\% with T1S1), received a median of 12 cycles of chemotherapy, and had relatively poor outcomes (36\% loss to follow up and $7 \%$ died). Over the same period, only $6 \mathrm{HIV}$-negative KS patients were treated at the CRAM [17].

\section{Participants}

New patients and chemotherapy-naïve established patients were screened for eligibility. Inclusion criteria included the following: age > 15 years; either T1 KS, or else
T0 KS not responding to 6 months of ART together with progressive/extensive lesions, B symptoms or significant impact on quality of life as judged by the physician; and willingness to follow up for 2 years. Cutaneous punch biopsy was used to confirm KS, but when not possible (for logistical or staffing reasons), the judgement of two physicians was considered sufficient to establish the diagnosis in the setting of typical advanced stage disease.

Exclusion criteria included history of receipt of doxorubicin (for any reason), Karnofsky score < 50 [18, 19], planned move out of the study area within 2 years, mental impairment leading to inability to contribute to data collection, pregnancy, breastfeeding, and (among women) refusal to use a birth control method other than condoms.

Cardiac function was assessed at screening by history and physical exam; patients with signs or symptoms of congestive heart failure were referred for echocardiography. If cardiac evaluation showed left ventricular ejection fraction $>50 \%$ and no structural abnormalities, the patient was eligible.

\section{Clinical definitions}

KS disease was classified according to the ACTG staging system, based on tumor extent $(\mathrm{T})$, immune system status (I), and evidence for HIV-associated systemic illness (S). Each variable is classified as good risk (0) or poor risk (1) [20]. These prognostic factors have been prospectively and independently validated [21].

Clinical outcomes were defined as follows, using previously-described criteria [14]:

- Complete Response (CR): Resolution of any detectable disease for $\geq 4$ weeks including $\mathrm{KS}$ associated edema or effusion.

- Partial Response (PR): Absence of new cutaneous or oral lesions, new visceral sites of involvement or the appearance or worsening of tumor-associated edema or effusions. In addition, at least one of the following applied:

a. $50 \%$ decrease in the number of previous skin lesions;

b. $\geq 50 \%$ of flattening of all previously raised lesions;

c. $\geq 50 \%$ decrease in the sum of the products of the largest perpendicular diameters of indicator lesions at enrolment;

d. Patient met the criteria for CR except for residual tumor associated edema or effusion;

e. The response lasted $\geq 4$ weeks.

- Overall Response (OR): Partial Response + Complete Response

- Stable Disease: Not meeting the criteria for progression, PR or CR

- Progressive Disease: One or more of the following: 
a. New visceral sites of involvement, or progression of visceral disease

b. New or increasing tumor-associated edema or effusion lasting at least 1 week and interfering with normal activities.

c. $\geq 25 \%$ increase in number of skin lesions.

d. A change in the character of $\geq 25 \%$ of previously "flat" skin lesions to "raised".

e. $\geq 25 \%$ increase in the sum of the products of the largest perpendicular diameters of the indicator skin lesions.

\section{Dosing of PLD}

$20 \mathrm{mg} / \mathrm{m}^{2}$ of body surface area (BSA) of PLD (Janssen, Belgium) was administered every 3 weeks until CR, or PR after having received at least 4 cycles of PLD, with good reported ART adherence and decreased pain. PLD was stopped after a cumulative dose of $550 \mathrm{mg} / \mathrm{m}^{2}$ of PLD.

PLD administration was delayed and rescheduled for the following: $<1000$ neutrophils $/ \mathrm{mm}^{3},<75,000$ platelets $/ \mathrm{mm}^{3}$, and serum creatinine and alanine aminotransferase $\geq 2$ times the upper limit of normal. PLD was held for serum hemoglobin concentrations $<10 \mathrm{~g} / \mathrm{dl}$, unless blood transfusion was available immediately following PLD infusion, in which case PLD was administered for hemoglobin between 8 and $10 \mathrm{~g} / \mathrm{dl}$.

Patients who previously met criteria for stopping PLD but who had new or worsening lesions, increased pain, or decreased quality of life over the course of follow-up were evaluated for re-initiation.

\section{Follow-up visits}

Study evaluations were scheduled at 3, 6, 9, 12, 18 and 24 months. At these visits, a physician performed a full history and physical exam and measured sentinel KS lesions. Blood samples to monitor for potential PLD toxicities were drawn prior to each PLD infusion, as described above. Blood was also drawn to monitor HIV control at each of the study evaluation visits.

The PHQ-9 questionnaire was administered at enrolment and annually thereafter. This depression screening tool has been validated in at least two sub-Saharan African settings, and scores $\geq 10$ have been shown to be valid for the diagnosis of major depression [22, 23]. Quality of life was assessed using the SF- $12^{\circ}$ questionnaire, which was administered at enrolment and every 6 months thereafter.

Information regarding the circumstances of death of patients who died during follow-up was conducted by interview with their surviving contacts.

\section{Safety monitoring}

Adverse events (AE) and serious adverse events (SAE) were evaluated at each study visit. An SAE was defined as an $\mathrm{AE}$ that resulted in death, was life-threatening, required hospitalization or prolongation of existing hospitalization, resulted in a persistent or significant disability or incapacity, required medical intervention intended to prevent one of the above outcomes, or was judged by the investigator as potentially serious. The causal relationship between PLD and a given AE or SAE was determined following Mozambican guidelines.

\section{Sample size and statistical analysis}

The target sample size was based on overall response. Assuming that $66 \%$ of participants would have CR or PR at 12 months [24], we calculated that 86 participants would be needed to show this response rate with a $10 \%$ margin. Given an expected transfer rate of $5 \%$ and loss to follow up of $30 \%$, a final sample size of 116 participants was set. Baseline characteristics of study participants were described using appropriate measures of frequency, central value and dispersion. Survival was estimated using the Kaplan-Meier method, and Coxproportional hazard modelling was used to explore associations between baseline characteristics and survival. Participants who achieved PR but later required restarting of PLD were censored at the time that PLD was restarted. Patients lost to follow-up were censored at the date of their last study visit.

Data was entered using EpiData version 3.0. The scoring of the SF- $12^{\circ}$ questionnaire was performed using Optum $^{\circ}$ PRO CoRE Smart Measurement ${ }^{\circ}$ System, version 1.4.7003.15542. All other analysis was performed using Stata v 15.0.

\section{Results}

\section{Description of participants}

Beginning March 1, 2016, a total of 183 patients were screened and 116 enrolled (Fig. 1). Sociodemographic characteristics of potential participants who were screened but not enrolled were generally similar to enrolled participants (Table 1). Five participants had signs of CHF warranting echocardiography; all had normal ejection fractions and were eventually included. Forty-six percent had been diagnosed with HIV in the 6 months preceding enrolment. Overall, $88 \%$ had started (or restarted) ART in the previous 6 months. Participants presented with advanced immunosuppression (median CD4 218, IQR [73-448]), and $93(80 \%)$ were receiving prophylactic co-trimoxazole at the time of enrollment.

At enrollment, 115 patients had cutaneous lesions: 40 had lesions too numerous to count, and of the 75 remaining patients, the median number of discrete lesions on the entire body was 17 (IQR: 6-30). In addition, $46 \%$ had visible mucosal lesions, and $23 \%$ had evidence of lesions in the respiratory or gastrointestinal tracts (by chest radiography, bronchoscopy, or upper endoscopy). 


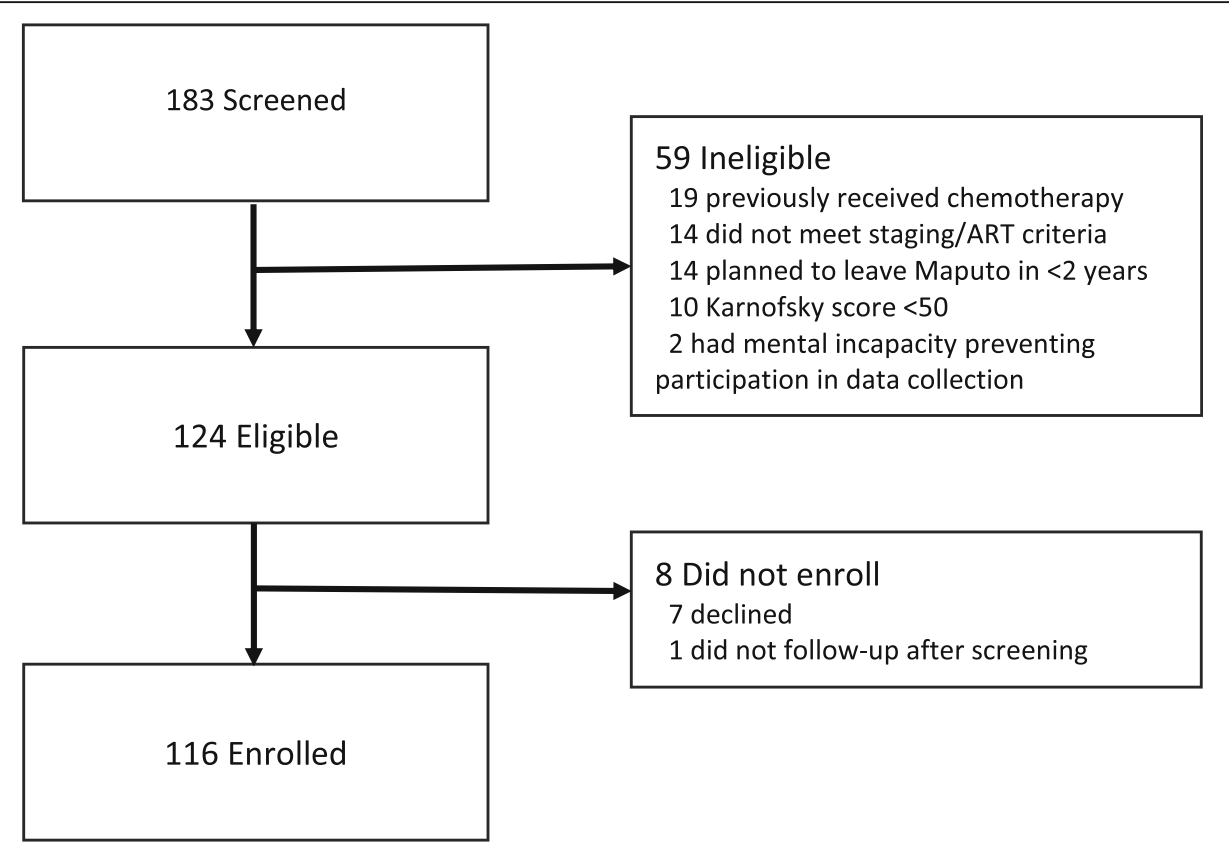

Fig. 1 Screening and enrolment

All 43 participants (37\%) who had biopsies had histologically confirmed KS.

\section{Outcomes}

At 24 months, 78 patients (67.2\%) were known to be alive, $23(19.8 \%)$ had died, and $15(12.9 \%)$ were lost to follow-up. Among the 15 participants lost to follow-up, median time in the study was 335 days (IQR 42-496, range 3-638). In bivariate analysis, there was no difference in survival by sex $(p=0.41$, Fig. 2a). Participants with $\mathrm{CD} 4<100$ at enrolment were more likely to die (HR 2.7, 95\%CI [1.2-6.2], $p=0.016$, Fig. 2b), as were participants with T1S1 disease at enrollment compared to those with T1S0 disease (HR 2.7, 95\%CI [1.1-6.4], $p=0.023$, Fig. 2c).

A total of 92 participants achieved CR or PR (OR= 80\%), including 15 participants (13\%) who achieved complete remission. Among the 92 patients who ever achieved CR or PR, 77 were alive at 24 months of follow-up, 7 were lost to follow-up, and 8 died. Among the 24 patients who never achieved CR or PR, 8 were lost to follow-up and 16 died.

Progression-free survival is presented in Fig. 3. At 1 year, progression-free survival was $65.5 \%$ (95\%CI [56.1$73.4]$ ), and at 2 years, progression-free survival was $50.7 \%$ (95\%CI [41.3-59.4]). In contrast to overall survival, male participants were less likely to have progression-free survival at 2 years (HR 0.4, 95\% CI [0.2, 0.7], $p=0.004$, Fig. 3a).

Among the 92 participants achieving CR or PR, $74 \%$ needed between 5 and 8 cycles of PLD to reach CR or
PR for the first time. 26 (28\%) of these patients eventually needed to restart PLD due to worsening symptoms or expanding lesion, of whom 20 survived to study exit, 2 were lost to follow up, and 4 died. The median time between achieving CR or PR and restarting PLD was 174 days (IQR 123-316).

\section{Adverse events}

Thirty-four SAEs were notified during the study period, including 23 deaths, 1 immediate transfusion reaction necessitating hospitalization, and 10 hospitalizations.

The circumstances of the 23 deaths were documented, and for many, it was impossible to make a single unifying diagnosis of the cause of death. Social problems (e.g., unstable housing, drug use, family strife) were common co-factors. Fourteen deaths occurred in hospital, and 9 at home. In general terms, they were classified as follows:

- 6 advanced HIV, death directly related to KS

- 6 advanced HIV, death unrelated to KS, but without other confirmed opportunistic infection (OI)

- 4 advanced HIV, with a confirmed other OI that predated study enrolment

- 2 advanced HIV, with a confirmed other OI that developed after study enrolment

- 1 bacterial pneumonia in a patient with CD4 $>500$

- 1 likely stroke

- 1 non-neutropenic sepsis of unclear origin

- 1 non-Hodgkin's lymphoma

- 1 cause of death could not be ascertained 
Table 1 Baseline characteristics of enrolled patients $(N=116)$

\begin{tabular}{|c|c|}
\hline Characteristic & $\begin{array}{l}\text { n (\%), unless otherwise } \\
\text { specified }\end{array}$ \\
\hline \multicolumn{2}{|l|}{ Sex, $n(\%)$} \\
\hline Male & $74(64)$ \\
\hline Female & $42(36)$ \\
\hline \multicolumn{2}{|l|}{ Age in years, $n(\%)$} \\
\hline $15-19$ & $1(1)$ \\
\hline $20-29$ & $19(16)$ \\
\hline $30-39$ & $55(47)$ \\
\hline $40-49$ & $43(26)$ \\
\hline$\geq 50$ & $11(10)$ \\
\hline \multicolumn{2}{|l|}{ Educational attainment, $n(\%)(N=114)$} \\
\hline No formal education & $5(4)$ \\
\hline Primary school & $51(44)$ \\
\hline Intermediate school & $50(44)$ \\
\hline High school or higher & $8(8)$ \\
\hline \multicolumn{2}{|l|}{ Kaposi stage, n(\%) } \\
\hline T1s0 & $80(69)$ \\
\hline T1S1 & $31(26)$ \\
\hline TOS1 & $2(2)$ \\
\hline TOSO & $3(3)$ \\
\hline Lymphedema present at enrolment & $83(72)$ \\
\hline \multicolumn{2}{|l|}{ Time since HIV diagnosis in months, $n(\%)$} \\
\hline $0-5$ & $53(46)$ \\
\hline $6-11$ & $13(11)$ \\
\hline $12-23$ & $18(16)$ \\
\hline$\geq 24$ & $32(28)$ \\
\hline \multicolumn{2}{|l|}{ Time on ART in months, $\mathrm{n}(\%)$} \\
\hline $0-5$ & $62(53)$ \\
\hline $6-11$ & $13(11)$ \\
\hline $12-23$ & $16(14)$ \\
\hline$\geq 24$ & $25(22)$ \\
\hline \multicolumn{2}{|l|}{ ART regimen, $n(\%)$} \\
\hline Efavirenz-based & $107(92)$ \\
\hline Nevirapine-based & $3(3)$ \\
\hline $\begin{array}{l}\text { Lopinavir/ritonavir or atazanavir- } \\
\text { based }\end{array}$ & $6(5)$ \\
\hline On treatment for TB, $n(\%)$ & $19(16)$ \\
\hline \multicolumn{2}{|l|}{ Laboratory values, median (IQR) } \\
\hline CD4 (cells/mm3) & $218(73-448)$ \\
\hline Serum Hemoglobin (g/dl) & $11.0(9.8-12.4)$ \\
\hline Platelets $\left(10^{3}\right.$ cells $\left./ \mu \mathrm{l}\right)$ & $284(222-360)$ \\
\hline $\begin{array}{l}\text { Absolute neutrophil count }\left(10^{3}\right. \\
\text { cells/ } \mu \text { l) }\end{array}$ & $2.7(2.0-3.6)$ \\
\hline Creatinine (mg/dl) & $0.8(0.6-1.0)$ \\
\hline Alanine aminotransferase $(\mathrm{U} / \mathrm{L})$ & $11(6-17)$ \\
\hline
\end{tabular}

The immediate infusion reaction occurred in a 21year-old female who developed acute shortness of breath and severe chest pain during her first PLD infusion. She was hospitalized, and symptoms resolved after treatment with hydrocortisone. The participant continued to receive further doses of PLD without incident and achieved partial remission. This was the only direct infusion reaction seen during the 894 doses of PLD administered during the study $(0.1 \%)$.

The 10 hospitalizations were due to progressive KS (4 patients), TB ( 2 patients), wasting syndrome (2 patients) and other OIs (2 patients).

Sixty-five AEs were notified in 33 individual participants (28.4\% of all enrolled). In terms of severity, 22 (38\%) were classified as mild, 31 (53\%) as moderate, and 5 (9\%) as severe; 46 (73\%) were judged linked to PLD. The most common AEs were hematologic abnormalities: neutropenia (12 events), anemia (15 events), neutropenia and anemia (21 events), isolated thrombocytopenia (2 events) and pancytopenia (3 events). Two cases of the hand-foot syndrome were notified. The first occurred in a 42-year old female who had received 6 doses of PLD, and the second occurred in a 36-year old male who had received 2 doses. Both cases had mild palmar and plantar erythema with mild desquamation, and both resolved within 2 weeks without treatment.

\section{Mental health and quality of life}

At enrolment, 10 patients (9\%) had PHQ-9 scores $\geq 10$, and of patients with subsequent evaluations, 3 of 102 (3\%) had a PHQ-9 score $\geq 10$ at their final study visit.

Baseline SF- $12^{\circ}$ scores were available for 113 participants. At enrolment, 65 patients $(58 \%)$ had a Physical Component Summary score below that of the general population, including 49 (43\%) who scored "Well Below". This proportion dropped significantly during follow up (Fig. 4a). For the Mental Component Summary, at enrolment, 21 patients (19\%) had a score below that of the general population, including $13(12 \%)$ who scored "Well Below". As with the Physical Component Summary, the proportion of those with scores below that of the general population decreased during followup (Fig. 4b). The most marked differences came in the Physical Component Summary in the first 6 months of follow-up. Each of the individual components (Physical functioning, Role physical, Bodily pain, and General health) improved between those two evaluations, and the average score among the cohort for three of the four components went from below the norm for the general population to above the norm.

\section{Discussion}

We describe the outcomes of the first 116 patients to receive PLD in Mozambique. PLD was safe and effective 


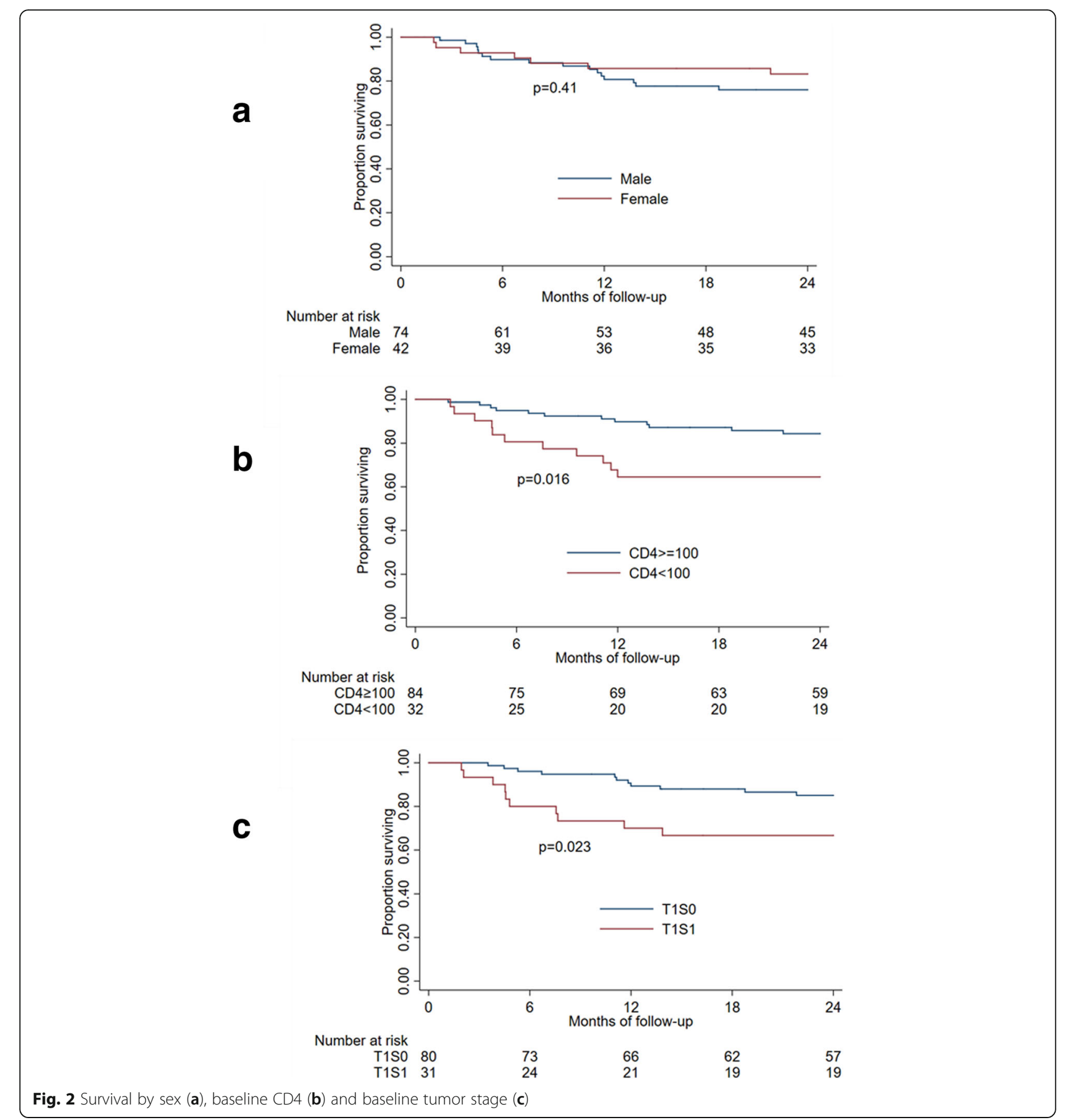

in this setting, and to our knowledge, we have described the mental health and quality of life of patients with HIV-related KS for the first time in Mozambique.

\section{Effectiveness of PLD}

Participants had significant KS disease at baseline, and many also presented with advanced immunosuppression. Despite this, the OR rate was $80 \%$. Given the severity of presentations, it is not surprising that a small minority of patients (13\%) ever achieved CR. Importantly, the number of cycles of chemotherapy needed to achieve first response was low ( $\leq 8$ cycles for $83 \%$ of participants achieving $\mathrm{CR}$ or $\mathrm{PR}$ ), much lower than previously reported with BV and ABV regimens in the same clinic, when patients received a median of 12 cycles of chemotherapy [17]. Receiving fewer doses of cytotoxic chemotherapy means fewer side effects, fewer hospitalizations and fewer clinic visits for patients, which is an important benefit of the PLD regimen. 

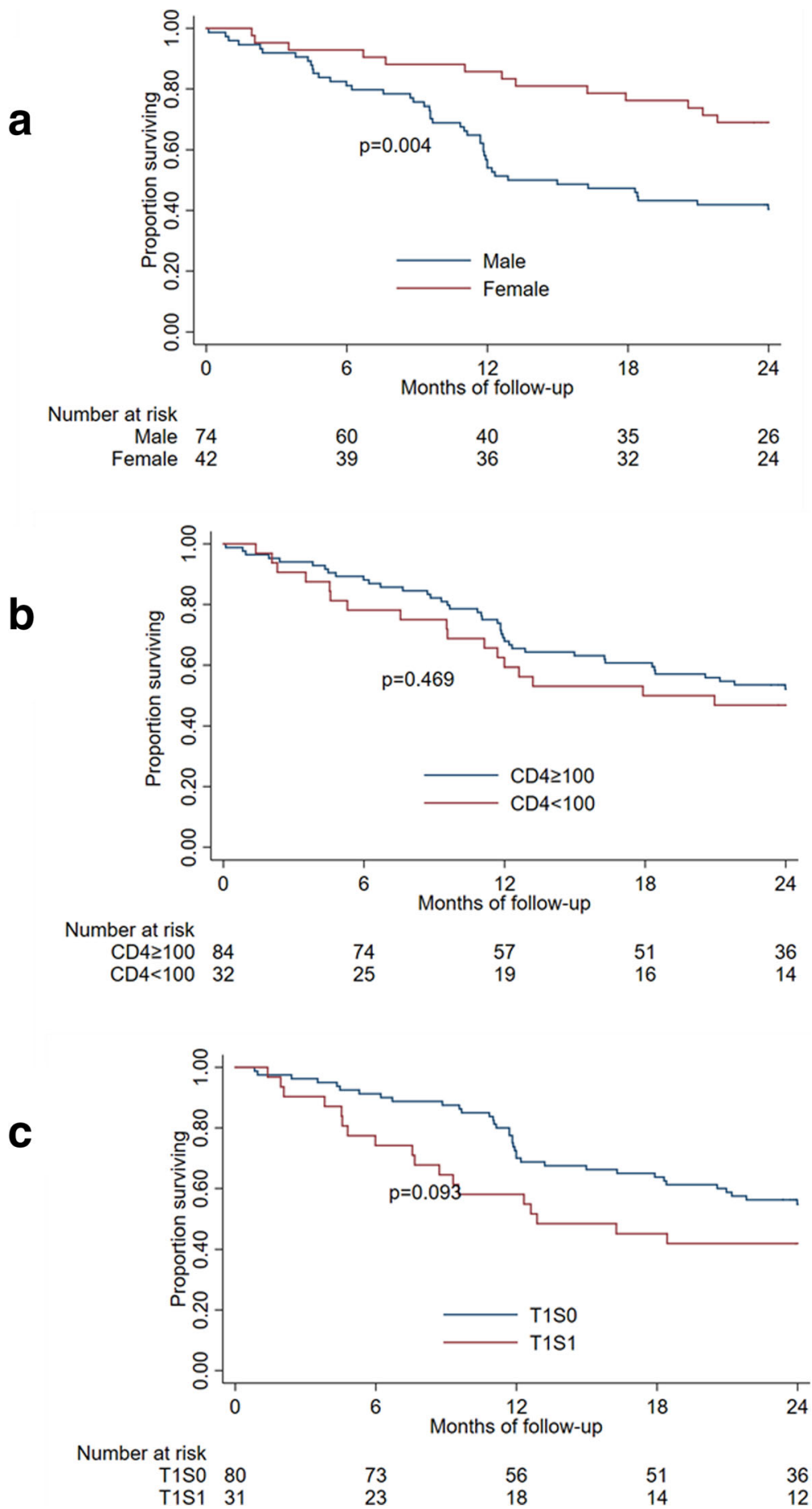

Fig. 3 Progression-free survival by sex (a), baseline CD4 (b) and baseline tumor stage (c)

$28 \%$ of patients who achieved CR or PR eventually needed additional doses of PLD. Although it is impossible to say with certainty, this phenomenon does not seem to be related directly to PLD. A few of these "relapses" occurred after interruption of ART, and others occurred in patients with massive baseline KS burden and significant lymphedema. But a majority occurred in patients with undetectable (or nearly undetectable) HIV viral load. Given that complete immune reconstitution is slow in ideal circumstances, it is unsurprising that some patients needed additional doses of PLD. These findings may also be partially explained by a decreased anti- 

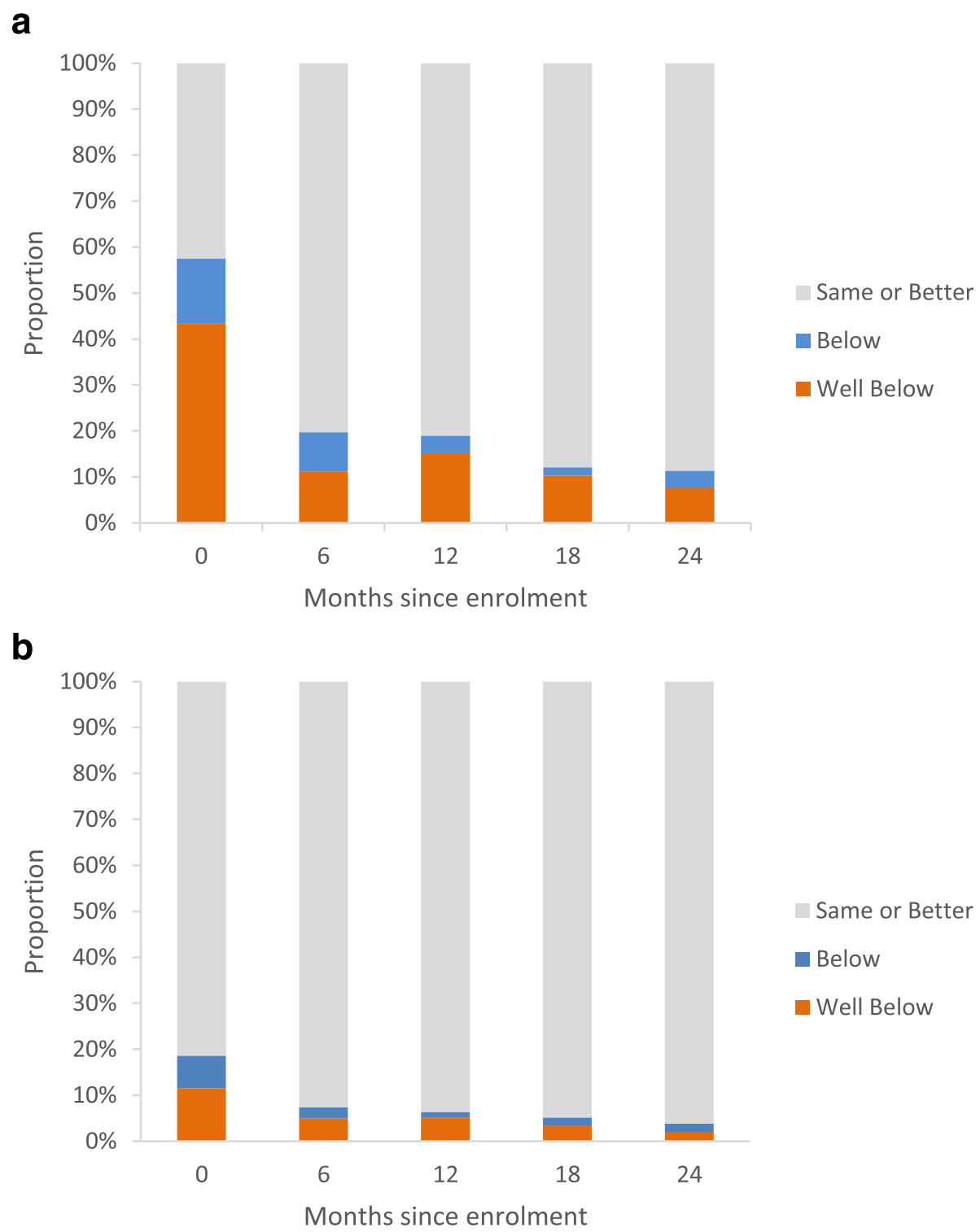

Fig. 4 SF- $12^{\varpi}$ scores benchmarked against general population. (a) Represents the Physical Component Summary and (b) represents the Mental Component Summary

HHV8 T-cell response that has been described in patients with KS (compared to the anti-HHV8 T-cell response seen in patients with asymptomatic HHV8 infection) [25].

Advanced KS and AIDS at baseline means that CR was likely an impossible goal for many participants. In this setting, it is reasonable for clinicians to focus on alleviation of pain, slowing KS disease progression, and improvement in quality of life, while at the same time achieving virologic suppression. The results suggest that it is reasonable to treat until symptoms have ameliorated (and not until lesions disappear) because many patients with severe baseline disease will eventually need to restart chemotherapy after initial response. Restarting PLD was not necessarily a bad prognostic indicator, as 20 of 26 of our patients who restarted survived until study exit.

\section{Safety of PLD}

Broadly speaking, PLD was safe and well-tolerated. The hematologic toxicities seen were generally of moderate severity, and not unexpected. And although some patients needed transfusions, the side effects of PLD were less limiting and less toxic to the patients than with the previous ABV regimen, and also those described with the use of paclitaxel monotherapy $[17,26]$. While data on the incidence of hand-foot syndrome in Sub-Saharan Africa are scarce, it is possible that the relatively lower 
doses and the three-week interval between doses may explain its rarity in this cohort.

We described an immediate infusion reaction, which was frightening for the patient and for the clinical staff. Acute-onset chest tightness and shortness of breath have been previously described in the literature, particularly during the first infusion of PLD [27]. Importantly, after full work-up, this patient was able to receive further doses of PLD without incident.

\section{Mortality and loss to follow-up}

Overall, mortality was high in this population. At 24 months of follow-up, $20 \%$ of study participants had died, and another $13 \%$ had been lost to follow-up. Most deaths came within the first year after enrolment, and participants with lower baseline CD4 and more advanced KS disease were more likely to die. When examining the individual causes of death, it becomes clear that most of those who died had complex medical and social situations.

In previous data from the CRAM, few patients receiving chemotherapy (7\%) were known to have died, but $36 \%$ were lost to follow-up. But a lack of strict contact tracing impeded understanding the reasons for loss to follow-up. Our current results suggest that a significant proportion of patients previously lost to follow-up actually died. Nonetheless, we note that, even in the worst-case scenario, if we assume that all patients lost to follow-up in this study died, the overall mortality in this group of patients receiving PLD (33\%) would be less than that of the historical cohort in the CRAM (43\%) [17].

It is important to note that these two analyses happened at different points in time. Many of the patients in the historical CRAM cohort were treated in an era when access to ART and VL monitoring were more difficult. There is clear understanding that ART is the cornerstone of KS treatment, and that its addition has greatly improved survival for KS patients [28]. Therefore, the high mortality seen during the first year of treatment underscores the importance of providing a full package of HIV care, including good counseling for ART compliance, VL monitoring, awareness of ART resistance patterns, and access to second- and third-line ART. It is also important to note that the specialized ambulatory clinic where the study took place was in a denselypopulated urban setting, where distances and travel time to the clinic generally did not exceed $90 \mathrm{~min}$, which may be different from rural settings.

\section{Psychosocial well-being}

One of the innovations of this study was to objectively monitor the psychosocial well-being of participants. PLD has led to increased quality of life for KS patients in high-income settings [16], but to our knowledge there has been little documentation of this in low-resource settings.

Our most striking finding was the improvement in the physical components of the SF- $12^{\circ}$ evaluation in the first 6 months of treatment with PLD. At baseline, pain and a sense of general ill-health - both components of the Physical Component Summary - drove quality of life scores to be significantly below those of the general population in many participants. At 6 months, the most important gains in the overall quality of life came because of a reduction in pain. These intuitive results provide evidence of the PLD's benefits, particularly for advanced lymphedematous presentations commonly seen in this setting, which have a major impact on mobility and morbidity.

\section{Improving chemotherapy regimens in sub-Saharan Africa}

The traditional ABV regimen is not ideal, because of substandard outcomes and an unfavorable side effect profile, so finding less toxic alternatives is urgent. Indeed, paclitaxel was recently shown to be superior to both a combination of bleomycin and vincristine and also to oral etoposide in a multi-centric trial in southern Africa, though we note that paclitaxel toxicities were largely the same compared to the vincristine/bleomycin group [26]. We are unable to compare our observational results with PLD with those from the paclitaxel trial, but future research in Africa should include head-to-head testing of PLD and paclitaxel. These standards of care in high-income settings have only been directly compared in smaller studies, and in Africa should have a special focus on safety and tolerability [29].

Nonetheless, given the lack access to even basic chemotherapy like ABV in most of sub-Saharan Africa $[30,31]$, this may be difficult. General health systems barriers include lack of medications, lack of clear guidelines, staff with little oncological training, few diagnostic and monitoring tools and poor infrastructure necessary to handle cytotoxic medications [30, 32, 33]. Expanding the use of PLD will therefore require increased supply and additional financing. Since the initiation of this study, PLD now appears on procurement lists of the Global Fund, which is a positive step. But to ensure access to PLD (and paclitaxel), drug manufacturers and international partners will need to work to lower prices, increase production capacity, and improve availability. In the meantime, early diagnosis of HIV and KS should be emphasized, to avoid the late presentations seen commonly in our setting.

\section{Limitations}

Our study has several limitations. First, the observational nature of the study makes it impossible to draw strict 
comparisons between PLD and previous regimens. Second, the exclusion of non-HIV-associated KS limits our ability to extrapolate on PLD's effectiveness in other populations. "Endemic" KS is common in Mozambique, and the seroprevalence of HHV8 has been reported as as high as 51\% [34]. Unfortunately, this is a population not treated at the specialized study site. Third, lack of specific data regarding ARV adherence limits interpretation of the root cause of relapses, which could be due to poor adherence, or in the setting of good adherence, virological resistance. Finally, the lack of biopsy confirmation in $57 \%$ of patients was unavoidable because of logistic and staffing issues.

\section{Conclusions}

These results show the effectiveness, safety, and tolerability of PLD as first-line chemotherapy for KS in a resource-limited setting. Moving from this positive experience in a specialized setting to broader uptake will require efforts to increase access to PLD and other new chemotherapies, integrated into a comprehensive plan to upgrade skills of health staff and infrastructure.

\section{Abbreviations}

ABV: Combination therapy with doxorubicin, bleomycin and vincristine: ACTG: AIDS Clinical Trial Group; AE: Adverse event; AIDS: Acquired immunodeficiency syndrome; ART: Antiretroviral therapy; BSA: Body surface area; BV: Combination therapy with bleomycin and vincristine; CR: Complete remission; CRAM: Centro de Referência de Alto-Maé; HR: Hazard ratio; HIV: Human immunodeficiency virus; IQR: Interquartile range; KS: Kaposi's sarcoma; MSF: Médecins Sans Frontières; Ol: Opportunistic infection; OR: Overall response; PHQ-9: Patient health questionnaire-9; PLD: Pegylated liposomal doxorubicin; PR: Partial remission; SAE: Serious adverse event

\section{Acknowledgements}

The authors thank Vini Fardhdiani, Loide Cossa, and Natercia Madeira for their assistance with data collection and management, and Dr. Gil Muvale and the clinical staff of CRAM for providing patient care. We thank Jessica Burry of the MSF Access Campaign for efforts to improve access to PLD in sub-Saharan Africa. We thank Sandrine Gruningen, Elisabeth Poulet and Alain Makinson for their guidance and feedback throughout the study. We especially wish to thank study participants for their time and participation.

\section{Authors' contributions}

MEC oversaw data collection, performed the analysis and wrote the first draft of the article. AGGZ was responsible for patient care and assisted with study implementation in the field. RM and GL participated in study design and provided support in patient management. BR and IC participated in study design. RFG participated in data analysis and writing of the article. LTT participated in study design, literature review, patient care and data interpretation. LM was responsible for study design and implementation. All authors made important intellectual contributions to the work and have agreed the final draft for submission.

\section{Funding}

Médecins Sans Frontières

\section{Availability of data and materials}

The datasets used and/or analyses during the current study are available from the corresponding author on reasonable request.

\section{Ethics approval and consent to participate}

The study protocol was reviewed and approved by the Comité Nacional de Bioética para a Saúde of Mozambique (Ref: 100/CNBS/2014) and the MSF-ERB
(Ref: 1338) and was carried out with the permission of national and local health authorities.

\section{Consent for publication}

Not applicable.

\section{Competing interests}

The authors declare that they have no competing interests.

\section{Author details}

${ }^{1}$ Epicentre, 14-34 Avenue Jean Jaurès, 75019 Paris, France. ${ }^{2}$ Médecins Sans Frontières, Maputo, Mozambique. ${ }^{3}$ Ministry of Health, Maputo, Mozambique. ${ }^{4}$ Médecins Sans Frontières, Geneva, Switzerland. ${ }^{5}$ University Hospitals of Geneva, Geneva, Switzerland.

Received: 7 October 2020 Accepted: 17 December 2020 Published online: 07 January 2021

\section{References}

1. Casper C. The increasing burden of HIV-associated malignancies in resource-limited regions. Annu Rev Med. 2011;62:157-70 Available from: http://www.ncbi.n/m.nih.gov/pubmed/20868276.

2. Dittmer DP, Krown SE, Mitsuyasu R. Exclusion of Kaposi sarcoma from analysis of cancer burden. JAMA Oncol. 2017:3:1429 [cited 2019 May 23]. Available from: http://www.ncbi.n/m.nih.gov/pubmed/28662221.

3. Carrilho C, Ferro J, Lorenzoni C, Sultane T, Silva-Matos C, Lunet N. A contribution for a more accurate estimation of the incidence of Kaposi sarcoma in Mozambique. Int J Cancer. 2012;132:988-9.

4. Globocan 2012: Estimated cancer incidence mortality and prevalance worldwide in 2012. Fact Sheets by Population. [cited 2017 Jul 26];Available from: http://globocan.iarc.fr/Pages/fact sheets_population.aspx.

5. Chu KM, Mahlangeni G, Swannet S, Ford NP, Boulle A, Van Cutsem G. AIDSassociated Kaposi's sarcoma is linked to advanced disease and high mortality in a primary care HIV programme in South Africa. J Int AIDS Soc. 2010;13:23 [cited 2017 Jul 26]. Available from: http://www.ncbi.nlm.nih.gov/ pubmed/20615222.

6. de Moore GM, Hennessey P, Kunz NM, Ferrando SJ, Rabkin JG. Kaposi's sarcoma: The Scarlet Letter of AIDS: the psychological effects of a skin disease. Psychosomatics. 41:360-3 [cited 2017 Jul 26]. Available from: http://www.ncbi.nlm.nih.gov/pubmed/10906360.

7. Bower M, Fox P, Fife K, Gill J, Nelson M, Gazzard B. Highly active antiretroviral therapy (HAART) prolongs time to treatment failure in Kaposi's sarcoma. AIDS. 1999;13:2105-11 [cited 2017 Jul 26]. Available from: http://www.ncbi.nlm.nih.gov/pubmed/10546864.

8. Bower M, Weir J, Francis $N$, Newsom-Davis T, Powles S, Crook T, et al. The effect of HAART in 254 consecutive patients with AIDS-related Kaposi's sarcoma. AIDS. 2009;23:1701-6 [cited 2017 Jul 26]. Available from: http://www.ncbi.nlm.nih.gov/pubmed/19550283.

9. Martin-Carbonero L, Barrios A, Saballs P, Sirera G, Santos J, Palacios R, et al. Pegylated liposomal doxorubicin plus highly active antiretroviral therapy versus highly active antiretroviral therapy alone in HIV patients with Kaposi's sarcoma. AIDS. 2004;18:1737-40 [cited 2017 Jul 26]. Available from: http://www.ncbi.nlm.nih.gov/pubmed/15280789.

10. Uldrick TS, Whitby D. Update on KSHV-epidemiology, Kaposi sarcoma pathogenesis, and treatment of Kaposi sarcoma. Cancer Lett. 2011;205:15062 Available from: https://www.ncbi.nlm.nih.gov/pmc/articles/PMC3085592/ pdf/nihms281953.pdf.

11. Di Lorenzo G, Konstantinopoulos PA, Pantanowitz L, Di Trolio R, De Placido S, Dezube BJ. Management of AIDS-related Kaposi's sarcoma. Lancet Oncol. 2007:8:167-76.

12. Rafiyath SM, Rasul M, Lee B, Wei G, Lamba G, Liu D. Comparison of safety and toxicity of liposomal doxorubicin vs conventional anthracyclines: a meta-analysis. Exp Hematol Oncol. 2012;1:10.

13. Martín-Carbonero L, Palacios R, Valencia E, Saballs P, Sirera G, Santos I, et al. Long-term prognosis of HIV-infected patients with Kaposi sarcoma treated with pegylated liposomal doxorubicin. Clin Infect Dis. 2008;47: 410-7 [cited 2017 Jul 26]. Available from: http://www.ncbi.nlm.nih.gov/ pubmed/18582203.

14. D.W. N, B.J. D, J.A. T, B.J. M, M.A. F, A. F-K, et al. Pegylated-liposomal doxorubicin versus doxorubicin, bleomycin, and vincristine in the treatment of AIDS-related Kaposi's sarcoma: Results of a randomized 
phase III clinical trial. J Clin Oncol. 1998;16:2445-51 Available from: http://ovidsp.ovid.com/ovidweb.cgi?T=JS\&PAGE=reference\&D=emed4 \&NEWS=N\&AN=1998225393.

15. Stewart S, Jablonowski H, Goebel FD, Arasteh K, Spittle M, Rios A, et al. Randomized comparative trial of pegylated liposomal doxorubicin versus bleomycin and vincristine in the treatment of AIDS-related Kaposi's sarcoma. J Clin Oncol. 1998;16:683-91.

16. Osoba D, Northfelt DW, Budd DW, Himmelberger D. Effect of treatment on health-related quality of life in acquired immunodeficiency syndrome (AIDS)-related Kaposi's sarcoma: a randomized trial of pegylated-liposomal doxorubicin versus doxorubicin, bleomycin, and vincristine. Cancer Investig. 2001;19:573-80 [cited 2017 Jul 26]. Available from: http://www.ncbi.nlm.nih.gov/pubmed/11486699.

17. Fardhdiani V, Molfino L, Zamudio AG, Manuel R, Luciano G, Ciglenecki I, et al. HIV-associated Kaposi's sarcoma in Maputo, Mozambique: Outcomes in a specialized treatment center, 2010-2015. Infect Agent Cancer. 2018;13.

18. Yates JW, Chalmer B, McKegney FP. Evaluation of patients with advanced cancer using the Karnofsky performance status. Cancer. 1980;45:2220-4 Available from: http://www.ncbi.nlm.nih.gov/pubmed/7370963.

19. Mor V, Laliberte L, Morris JN, Wiemann M. The Karnofsky performance status scale. An examination of its reliability and validity in a research setting. Cancer. 1984;53:2002-7 Available from: http://www.ncbi.nlm.nih. gov/pubmed/6704925.

20. Krown SE, Metroka C, Wernz JC. Kaposi's sarcoma in the acquired immune deficiency syndrome: a proposal for uniform evaluation, response, and staging criteria. AIDS Clinical Trials Group Oncology Committee. J Clin Oncol. 1989;7:1201-7 [cited 2017 Jul 10]. Available from: http://www.ncbi. nlm.nih.gov/pubmed/2671281.

21. Boffi El Amari E, Toutous-Trellu L, Gayet-Ageron A, Baumann M, Cathomas G, Steffen I, et al. Predicting the evolution of Kaposi sarcoma, in the highly active antiretroviral therapy era. AIDS. 2008;22: 1019-28 [cited 2017 Jul 26]. Available from: http://www.ncbi.nlm.nih. gov/pubmed/18520345

22. Nakku JEM, Rathod SD, Kizza D, Breuer E, Mutyaba K, Baron EC, et al. Validity and diagnostic accuracy of the Luganda version of the 9-item and 2-item Patient Health Questionnaire for detecting major depressive disorder in rural Uganda. Glob Ment Heal. 2016:3:e20 [cited 2019 Apr 15]. Available from: http://www.ncbi.nlm.nih.gov/pubmed/28596888.

23. Gelaye B, Williams MA, Lemma S, Deyessa N, Bahretibeb Y, Shibre T, et al. Validity of the patient health questionnaire-9 for depression screening and diagnosis in East Africa. Psychiatry Res. 2013;210:653-61 [cited 2019 Apr 15]. Available from: https://linkinghub.elsevier.com/ retrieve/pii/S0165178113003909.

24. Mosam A, Shaik F, Uldrick TS, Esterhuizen T, Friedland GH, Scadden DT, et al. A randomized controlled trial of highly active antiretroviral therapy versus highly active antiretroviral therapy and chemotherapy in therapy-naive patients with HIV-associated Kaposi sarcoma in South Africa. JAIDS J Acquir Immune Defic Syndr. 2012;60:150-7 [cited 2017 Sep 13]. Available from: http://www.ncbi.nlm.nih.gov/pubmed/22395672.

25. Guihot A, Dupin N, Marcelin A-G, Gorin I, Bedin A-S, Bossi P, et al. Low T cell responses to human herpesvirus 8 in patients with AIDS-related and classic Kaposi sarcoma. J Infect Dis. 2006;194:1078-88 [cited 2019 Jul 2]. Available from: https://academic.oup.com/jid/article-abstract/194/ 8/1078/869607.

26. Krown SE, Moser CB, Macphail P, Matining RM, Godfrey C, Caruso SR, et al. Treatment of advanced AIDS-associated Kaposi sarcoma in resource-limited settings: a three-arm, open-label, randomised, non-inferiority trial. Lancet. 2020; [cited 2020 Mar 9]. Available from: www.thelancet.com.

27. Castells MC, Tennant NM, Sloane DE, Hsu Fl, Barrett NA, Hong Dl, et al. Hypersensitivity reactions to chemotherapy: Outcomes and safety of rapid desensitization in 413 cases. [cited 2019 May 2]. Available from: https://www.jacionline.org/article/S0091-6749(08)00762-8/pdf.

28. Sengayi MM, Kielkowski D, Egger M, Dreosti L, Bohlius J. Survival of patients with Kaposi 's sarcoma in the South African antiretroviral treatment era : A retrospective cohort study. S Afr Med J. 2017;107:8716 [cited 2018 Jan 4]. Available from: http://www.samj.org.za/index.php/ samj/article/view/12077.

29. Cianfrocca M, Lee S, Von Roenn J, Tulpule A, Dezube BJ, Aboulafia DM, et al. Randomized trial of paclitaxel versus pegylated liposomal doxorubicin for advanced human immunodeficiency virus-associated Kaposi sarcoma:
Evidence of symptom palliation from chemotherapy. Cancer. 2010;116: 3969-77 [cited 2019 May 23]. Available from: https://www.ncbi.nlm.nih.gov/ pmc/articles/PMC3157242/pdf/nihms314205.pdf.

30. Farmer P, Frenk J, Knaul FM, Shulman LN, Alleyne G, Armstrong L, et al. Expansion of cancer care and control in countries of low and middle income: a call to action. Lancet. 2010;376:1186-93.

31. Sitas F, Parkin DM, Chirenje M, Stein L, Abratt R, Wabinga H. Part II: Cancer in indigenous Africans-causes and control. Lancet Oncol. 2008;9: 786-95.

32. Kerr DJ, Midgley R. Can we treat cancer for a dollar a day? Guidelines for low-income countries. N Engl J Med. 2010;363:801-3.

33. Krown SE. Treatment strategies for Kaposi sarcoma in sub-Saharan Africa: challenges and opportunities. Curr Opin Oncol. 2011;23:463-8 Available from: http://www.pubmedcentral.nih.gov/articlerender.fcgi?artid=346583 9\&tool=pmcentrez\&rendertype $=$ abstract.

34. Ceffa S, Buonomo E, Altan AMD, Erba F, Germano P, Guidotti G, et al. Seroprevalence of HHV8 in a cohort of HIV-negative and HIV-positive patients in Mozambique. Ann Ig. 2007;19:519-23 [cited 2020 Dec 8]. Available from: https://pubmed.ncbi.nlm.nih.gov/18376572/.

\section{Publisher's Note}

Springer Nature remains neutral with regard to jurisdictional claims in published maps and institutional affiliations.

Ready to submit your research? Choose BMC and benefit from:

- fast, convenient online submission

- thorough peer review by experienced researchers in your field

- rapid publication on acceptance

- support for research data, including large and complex data types

- gold Open Access which fosters wider collaboration and increased citations

- maximum visibility for your research: over $100 \mathrm{M}$ website views per year

At $\mathrm{BMC}$, research is always in progress.

Learn more biomedcentral.com/submissions 